\title{
CDISC SDTM PK Unit of Measure Milligram Dose Terminology
}

National Cancer Institute

\section{Source}

National Cancer Institute. CDISC SDTM PK Unit of Measure Milligram Dose Terminology. NCl Thesaurus. Code C128685.

Terminology associated with the PK unit of measure milligram dose codelist of the Clinical Data Interchange Standards Consortium (CDISC) Study Data Tabulation Model (SDTM). 